\title{
Academic innovation: are we truly ready for it?
}

\author{
P. E. Hänninen \\ pekka.hanninen@utu.fi
}

Department of Cell Biology and Anatomy, Institute of Biomedicine University of Turku Tykistökatu 6, 20520 Turku, Finland

Optics has been in the headlines this year due to the UN-sponsored International Year of Light 2015 (IYL 2015), and due to its presence in the 2014 Nobel Prize awards. The purpose of this article is to highlight the innovation-enabling elements that were behind the work of one of the Nobel Laureates - and the stream of innovations that followed, beyond the Nobel work. I will further, from this and my personal experience, expand some thoughts on the enabling elements of academic innovation and draw some conclusions - and, in particular, try and answer the question "How can academic success be repeated?"

[DOI: http://dx.doi.org/10.2971/jeos.2015.15044i]

Keywords: Innovation, peer-review

\section{INTRODUCTION}

Since the early 90's, Europe has come a long way - economically, socially, mentally and, of course, in science. This seems to be especially true when observed from the northernmost edge of Europe. Back in early 1993 when Stefan Hell joined our group, this northernmost edge was far, far away from those who did not believe in his ideas for breaking the diffraction limit, and the rest of the ideas that we had were of even less importance to them. But, because of this distance, Stefan got "valuable time to think" [1] - and also the necessary funding. The Academy of Finland was bold enough to fund the "impossible" and even that decision was not easy [2]. Stefan Hell's success did not come without taking risks indeed considerable risks, but it is easy to agree now that these risks have paid off not only in scientific terms, but also in other ways.

The story of Stefan Hell became mingled with ours by what seemed like a mere chance - a trick played by Lady Fortune but thinking now afterwards, luck does not follow chance but rather circumstances - and circumstances are created by active pursuit of one's goal.

\section{VISION - "THE CIRCUMSTANCES"}

When the Turku based company Wallac had managed to get its Lanthanide luminescence based TRF-product DELFIA [3][7] on the market, Erkki Soini, then the director of research at the company and the "father" of technology at the company, started considering the future. The bioassays of that time were based on the average of an ensemble of target molecules in a cuvette - providing only information about the concentration of the target molecule. In the mid 80's the research at the company adopted a new goal, set by Erkki Soini - "Closer to the Cell". The challenges of the future should be met by observing events at the cellular and molecular levels. With this research strategy the company became involved in developing differ- ent microscopy tools. It was far from clear what the future products on this path should look like but the microscopy initiative was used also as a learning and networking platform. One of the ideas evolving was the use of time-resolved fluorescence (TRF)-labels for microscopy to suppress unwanted background and thus increase the sensitivity of observation at the cellular level [8]. However, it was clear that the use of lanthanide labels would not provide sufficient signal to move forward towards targets at subcellular level and beyond.

Since the company, by ownership, had close ties with the Stockholm area in Sweden, Erkki Soini searched also for collaboration there. Discussions took place with the pioneers of fluorescence correlation spectroscopy (FCS), Rudolf Rigler $[9,10]$ and especially with Nils Åslund (Confocal microscopy) [11]. Confocal fluorescence microscopy provided high sensitivity of detection from small volumes - statistically analyzing fluorescence fluctuations down to the single molecule level with FCS [10], although detection of individual molecules came in firstly with the work of Moerner [12] and others (review of the development by Weiss [13]). Soini's quest was purely industrial to begin with - he was searching for new products, so generating new science was a by-product, if at all. In October 1986 Erkki had the possibility of spending some time at the European Molecular Laboratory - and he took that chance, spending altogether 6 months looking into the future inspired by the work at EMBL. It was the confocal microscopy initiative that attracted him. How he could turn this technique into new business for the company was far from clear but, based on his personal gut feeling, he decided that this was the direction in which to go. 


\section{THE MEANS - ACADEMIC FUNDING}

Without pointing a finger at any particular individual, radical thinking is often enough discredited by peers, and even by meritorious scientists - without a good rationale, by the use of carefully selected words. Words such as "there are still open questions on whether or not it has been proven" or "it does not appear to perform in accord with its promises" are enough to kill a project and even a career, when spoken by a person with a reputation high enough to 'outrank' those presenting new ideas. The "majority opinion" based on established "knowledge" may well prevent creative thinking. Majority opinion is also a well-known illusion: a mere $10 \%$ of committed population has been shown to be the turning point for social concensus [14]. In science our personal impact plays such a major role that, in a smaller field, a single leader of opinion can kill the greatest of ideas. Another burning issue is the often-criticized peer-review system [15]-[17]. Until now the scientific community has been unable to come up with anything better - rather the opposite. In many cases peer-review has gained the status of a gate-keeper, a task that a review conducted by only a few scientists should never have.

Back in 1992, Stefan Hell faced this situation. His academic funding was running out and his ideas were doubted. The really harsh criticism kicked in much later - but we all know how hard it can be for a young scientist to get funding, even if the stars shine in the right constellation and the research is in mainstream. Stefan's luck seemed to be running out. At that time the option of coming to Finland came at the last moment. The corner-stone for Stefan personally was that there was academic funding to give him the freedom that he needed - and that was provided by the Academy of Finland. The decision process at the Academy of Finland was exceptional: the decision-making body, the Council for Natural Sciences, debated the application heavily and then decided to call us for an interview and presentation. The final decision was pushed through by the biologists, with the physicists opposing [2]. This unusual procedure was finalized by appointing a followup committee for the project - while usually the process was handled on paper, with the decisions mailed back to the applicants.

In the early summer of 1994, the follow-up committee concluded, after a mere 18 months of the four-year funding: "The project has achieved all its goals and beyond" [18]. Back then it was already clear to those following closely that something extraordinary was evolving.

\section{MEANS - THE PEOPLE}

In 1986 Erkki Soini had gone through all the enabling technologies that were later going to lead to the innovations behind the 2014 Nobel Price in Chemistry. He did not have any idea of how to realize his dream of a new analytical approach but, as a pragmatic person, he did not feel that the idea needed to be ready right away and rather chose to follow his intuition and therefore tried to engage the right people working in this area to study the field more closely. This path was also encouraged by his old friend at University of Turku: Anatomy
Professor Mikko Niemi, a central influencer of Finnish medical research and education from the 1960s until the 1990s. In 1988 Erkki Soini agreed with Kai Simons, the head of the Cell Biology program at EMBL, that someone from Finland should join the confocal microscopy group in order to learn more about the technology and help realize the next version of EMBL's own confocal microscopes, one of which should then be delivered back to Finland. I was then sent to EMBL as this "someone", in the early fall of 1988.

As a starting researcher at the Tampere University of Technology, I was fascinated by the new world of science where I could explore my ever curious mind and solve problems and be a part of a team developing new image processing algorithms. To my good fortune, I was able to start my scientific career within the group headed by academy professor Yrjö Neuvo and in an atmosphere of a type that would later become instrumental in the development of mobile telephony by the Nokia Corporation [19]. Contact with Erkki Soini and Wallac came through Yrjö Neuvo and a joint project where Wallac had an interest in image processing for their future projects within microscopy and the biomedical field in general. My task at EMBL was to integrate into the team of engineers and build the group's own confocal microscopes [20]. Stefan Hell joined the group two years later. Stefan's work fascinated me to the point that my group leader told me not to interfere with it but to concentrate on my own tasks - so we talked in the evenings and became firstly more friends than scientists working together. For me, supporting Stefan was also a matter of loyalty to a friend in need - and, upon my return to Finland in 1992, I was asked to set up a new research environment for optics at the newly built BioCity in Turku. Stefan's help was also more than welcome since, after only 4 years in the field of optics, I felt myself to be more of a software engineer than a physicist. At the EMBL, Stefan was developing $4 \mathrm{Pi}$ microscopy [21] - so we took it from there and developed the technique further, bringing it closer to the actual applications [22]. The fact that we had a flexible open desktop set-up enabled us also to explore various ideas beyond the 4Pi microscopy. One of the key ideas for increasing the resolution was the joint action of two photons.

In Cornell, the development of two-photon microscopy had started earlier [23] and the whole microscopy development society was excited about this new way of imaging that could alleviate some of the key problems of confocal imaging: bleaching and penetration depth. We followed on this path, but for different reason - at first the objective was to reduce the inherent side lobes of 4Pi microscopy but, further along the path, we began to study the method for the purpose of resolution enhancement in general. One of the things that we realized rather quickly was that to be able to make two-photon excitation images, we did not need to turn our Ti:Sapphire on to mode-locked operation - but could run the experiments with a continuous working $(C W)$ cavity and somewhat higher average power [24]. Furthermore we realized that the original concept was limited to using femtosecond lasers - so we expanded the idea of $C W$ operation into a patent application and a subsequent patent [25] that came in handy for the microscope manufacturer that obtained the license, which did not win us any extra points at Cornell. 
The two-photon processes kept us going. Stefan kept on thinking about creating a switch with two independently controllable photons, while I was making measurements and confirming different properties of two-photon excitation that would later on lead into the development of a new in-vitro diagnostic instrumental platform and methodology [26]-[28]. The first publication about this possibility of utilizing independent photons was purely theoretical, without a vision of how this could be realized [29] - but the next one revealing the ideas behind stimulated-emission depletion (STED-) microscopy [30] and ground-state depletion (GSD-) microscopy [31] had clear plans that needed to be followed.

STED and GSD were not easy - nor was my approach of trying to find a solution of utilizing two-photon excitation in an affordable set-up for in-vitro diagnostic purposes. So we both were looking for solutions that would help us and numerous ideas were tried out. One seemingly promising approach was frustrated energy transfer $[32,33]$ - but we quickly realized its limitations and left the approach for a rainy day.

The inherent problem of the early STED implementation was the need for a pulsed depletion laser - which made the first experiments complicated and the price of a setup became horrendous. It also caused problems with the dyes that were common in biology - new STED-specific labels were needed. After the Nobel Prize was awarded, I have had discussions with Stefan about the history and his time in Turku - and one of the things that somewhat bothers him still is the fact that, although STED was gradually pushed through, we were, back then, sitting on a much simpler approach: CW-STED. The CW solution [34] does not have the complication, with pulsed sources, of synchronisation, nor it does impose such limits on the usable wavelengths - and truly, we were really sitting on this solution without realizing it. We had the lasers to perform CW STED and, most of all, we had just shown how CW lasers could be used in an area where the "absolute dogma" was to use femtosecond pulsed lasers.

Our work diverged into different directions and, at the end of 1996, Stefan moved back to Germany and Göttingen - and this is where I would like to stop and analyze how did all this happen and what were the enabling elements from my point of view.

\section{THE CHILD WITHIN}

Clayton Christensen, a Harvard Business School professor, has postulated in his book "Innovators Dilemma" [35], that large companies fail to recognize disruptive technologies and are trapped in their own ways of working - and disruptive technologies take over. Although the mechanisms of science are not the same as those of business I would like to claim that this same idea applies to science: mainstream science does not recognize innovation. Furthermore, since science does not have the same mechanisms as business, the mainstream is not truly threatened by the new innovations - so why does the mainstream scientist sometimes oppose new ideas so fiercely?

The 2014 Nobel Prize laureates in both physics and chemistry all had to fight against the mainstream, people who did not believe in them but rather the opposite. In fact, looking into the history of Nobel laureates, many of them had hard times and even got fired for doing things that lead to the Prize (e.g. Susumu Tonegawa) [36]. Taking risks should be normal in science but it was and still is a "luxury" only for those who are most persistent and do not yield to authority. It is clear that we should allow "the child within" ourselves to take more responsibility, but the child is mostly discouraged rather than encouraged. This is a well-recognized problem and there are also efforts to find solutions to this. However, so many of us depend on the incremental science funding that the solutions, in my opinion, are only marginal - the vast majority of us are forced into the mainstream.

Let us look at the elements on which Stefan Hell's success was based:

Firstly - Stefan had a solid background as a physicist, that was easy to recognize and he was also progressing in his work, with more results than promises. This alone should have been enough but it was not.

Secondly - the role of mentoring. A true mentor gives without claiming ownership. Far too often do the ideas become those of a senior group leader. A true mentor will allow the junior scientists to grow; both Stefan and I had this opportunity during the 90's with Erkki Soini.

A good mentor encourages one to aim high, but to stay with one's feet on the ground. Erkki Soini once said to me that resolution improvement is useful if it is by an order of magnitude or higher...

- Stefan Hell.

Thirdly - risk funding. Of all the costs that were incurred during our project, only about one third came from the Academy of Finland. The rest was "curious" industrial money that was either donated to us to set up the research group or received through industry collaboration contracts. Although the science funding from the Academy was important, we could have managed without - not the other way around.

Fourthly - the right atmosphere. Innovation and new ideas were the "kings" of our working group and because of the industrial background, every idea was also put on to the "testbench" of potential exploitation. We had a free hand to look in all directions, so long as the idea contained the element of exploitability. Science does not live for itself but for the society around us, the question of how to exploit the results is always valid - although the results within different fields of sciences vary tremendously.

So what is my suggestion on how to improve the science outcomes and repeat success stories such as that of Stefan Hell?

Firstly, fix the instruments that enable science - true science does not live in castles nor does it follow the rules set by the mainstream. You can have business people lead science projects and let them pick the projects, giving chances to seemingly crazy ideas - without the humiliation of peer-review. 


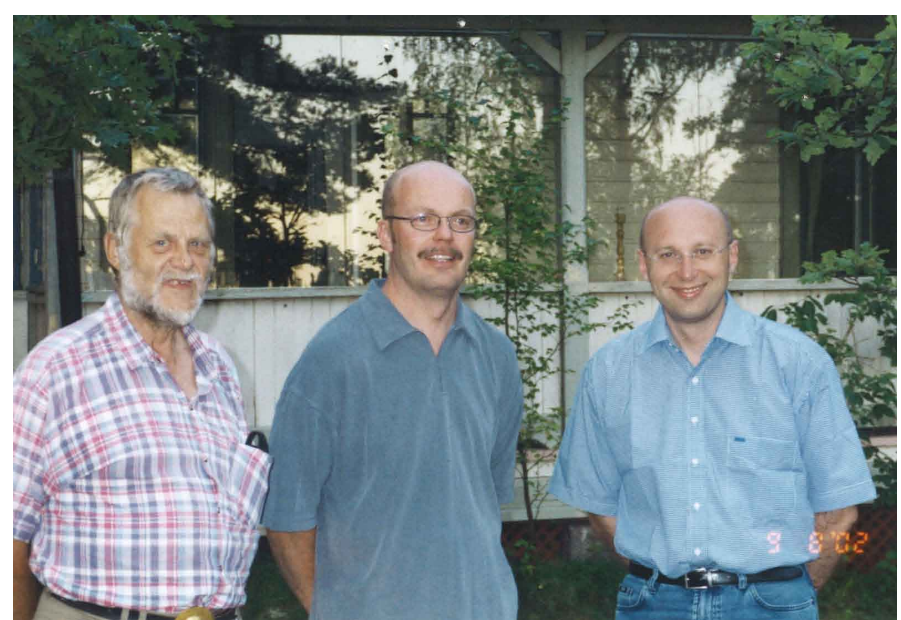

FIG. 1 Erkki Soini (left), Pekka Hänninen and Stefan Hell in 2002

Most of the money that is put into science goes to waste anyway, by definition, so: "Why don't we just play it a bit riskier?" and "Do not be trapped by dogma" [37].

Secondly, put all your trust into education and educators - the best scientists will be the best educators and mentors. Without a solid basis and dedicated support for all those seeking higher education, we will not have the best minds and ideas that could again change the ways we think about microscopy, lighting - and so on. Education is too often like sports in clubs - the best coaches want to support the best athletes, although these coaches are the ones that should work with children. Do not kill the innovation but nurture it and allow it to grow and only those who have ideas themselves can do that.

Thirdly, allow innovative minds to lead their lives like artists or world-class athletes. Administration and rules do not cope well with innovation - so why do we so often revert to the safety of the "rules" or give the administrators the freedom to exercise what they do best - at our expense. We need to take a stand in the administrative mess of today's world, in order to transform our world - instead of allowing the good hearted and self-willed administrators to do what they think is best for us.

\section{ACKNOWLEDGEMENTS}

PH wishes to express his deepest gratitude to Erkki and Stefan for their help with preparation of this article - and, of course, having the opportunity to be part of the story.

\section{References}

[1] M. Ehrenberg, The Nobel Prize in Chemistry 2014 - Presentation Speech (Stockholm, 2014).

[2] M. Kulomaa, Personal communication (Finland, 2006).

[3] 0. H. Meurman, I. A. Hemmilä, T. N. Lövgren, and P. E. Halonen, "Time-resolved fluoroimmunoassay: a new test for rubella antibodies," J. Clin. Microbiol. 16, 920-925 (1982).

[4] H. Siitari, I. Hemmilä, E. Soini, T. Lövgren, and V. Koistinen, “Detection of hepatitis B surface antigen using time-resolved fluoroim-

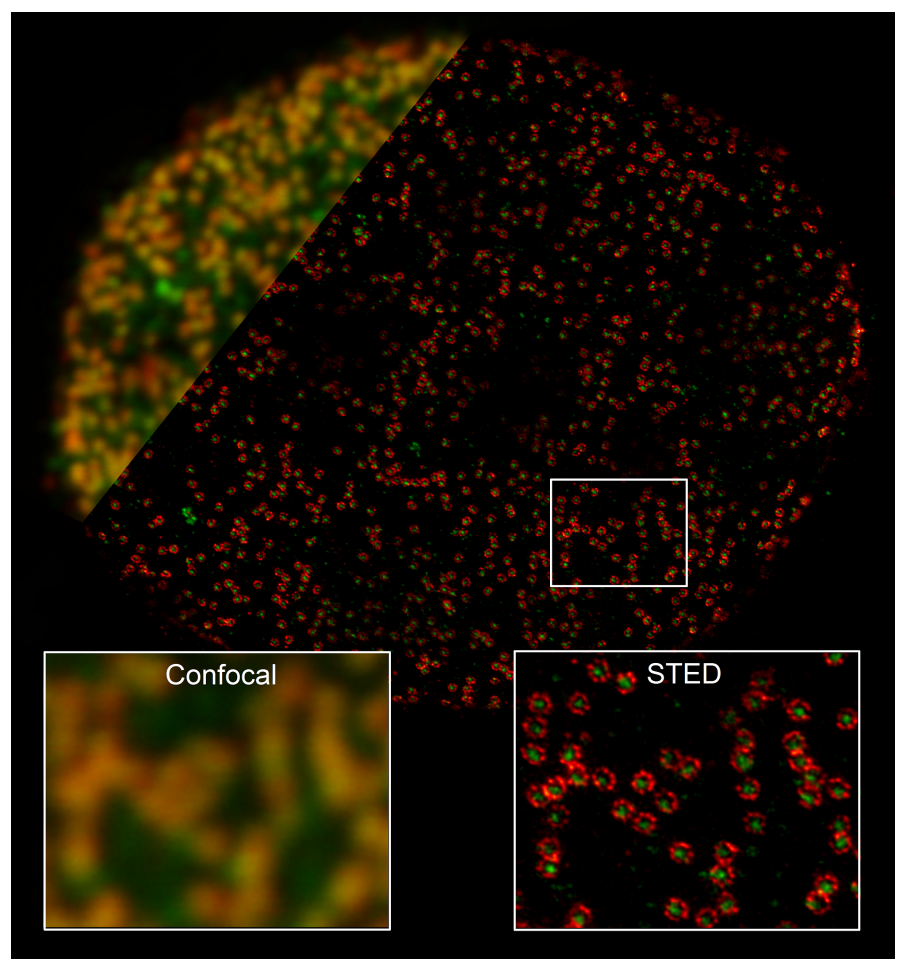

FIG. 2 STED nanoscopy of nuclear pore complex substructure in an intact nucleus. Reproduced by courtesy of Abberior Instruments $\mathrm{GmbH} /$ Stefan W. Hell (2014).

munoassay," Nature 301, 258-260 (1983).

[5] P. Halonen, 0. Meurman, T. Lövgren, I. Hemmilä, and E. Soini, “Detection of viral antigens by time-resolved fluoroimmunoassay," Curr. Top. Microbiol. Immunol. 104, 133-146 (1983).

[6] E. Soini, and H. Kojola, "Time-resolved fluorometer for lanthanide chelates-a new generation of nonisotopic immunoassays," Clin. Chem. 29 (1), 65-68 (1983).

[7] N. J. Marshall, S. Dakubu, T. Jackson, and R. P. Ekins, "Pulsed light, time resolved fluoroimmunoassay," in Monoclonal antibodies and developments in immunoassay, R. Ekins, and A. Albertini, eds., 101-108 (Elsevier, Amsterdam, 1981).

[8] L. Seveus, M. Vaisala, I. Hemmila, H. Kojola, G. M. Roomans, and E. Soini, "Use of fluorescent europium chelates as labels in microscopy allows glutaraldehyde fixation and permanent mounting and leads to reduced autofluorescence and good long-term stability," Microsc. Res. Techniq. 28, 149-154 (1994).

[9] M. Ehrenberg and R. Rigler, "Fluorescence correlation spectroscopy applied to rotational diffusion of macromolecules," Q. Rev. Biophys. 9, 69-81 (1976).

[10] R. Rigler, Ü. Mets, J. Widengren, and P. Kask, "Fluorescence correlation spectroscopy with high count rate and low background: analysis of translational diffusion," Eur. Biophys. J. 22, 169-175 (1993).

[11] K. Carlsson, P. E. Danielsson, R. Lenz, A. Liljeborg, L. Majlöf, and N. Aslund, "Three-dimensional microscopy using a confocal laser scanning microscope," Opt. Lett. 10 (2), 53-55 (1985). 
[12] W. E. Moerner and L. Kador, "Finding a Single Molecule in a Haystack," Anal. Chem. 61 (21), 1217A-1223A (1989).

[13] S. Weiss, "Fluorescence spectroscopy of single biomolecules," Science 283 (5408), 1676-83 (1999).

[14] J . Xie, S. Sreenivasan, G. Korniss, W. Zhang, C. Lim, and B. K. Szymanski, "Social consensus through the influence of committed minorities," Phys. Rev. E 84 (1), 011130 (2011).

[15] R. Smith, "Peer review: a flawed process at the heart of science and journals," J. Roy. Soc. Med. 99 (4), 178-182 (2006).

[16] "Peer review is fraught with problems, and we need a fix." http://theconversation.com/peer-review-is-fraught-withproblems-and-we-need-a-fix-34212 [Accessed: 08-Jun-2015].

[17] "The easy way to fix peer review: Require submitters to review first." http://www.slate.com/articles/life/education/2014/07/the _easy_way_to_fix_peer_review_require_submitters_to_review _first.html [Accessed: 08-Jun-2015].

[18] P. Hänninen, “Academy project 4155/4011/92 'Confocal Microscopy' - meeting protocol," 1994.

[19] M. Häikiö, textsıBit Bang: Yrjö Neuvo ja digitaalinen kumous (Yrjö Neuvo and digital revolution (Suomalaisen Kirjallisuuden Seura, Helsinki, 2013) in Finish.

[20] E. H. Stelzer, R. Stricker, R. Pick, C. Storz, and P. Hanninen, "Confocal Fluorescence Microscopes For Biological Research," in Proceedings to 1988 International Congress on Optical Science and Engineering, 146-151 (SPIE, Hamburg, 1989).

[21] S. Hell, and E. H. K. Stelzer, "Fundamental improvement of resolution with a $4 \mathrm{Pi}$-confocal fluorescence microscope using twophoton excitation," Opt. Commun. 93 (5-6), 277-282 (1992).

[22] P. E. Hänninen, S. W. Hell, J. Salo, E. Soini, and C. Cremer, "2Photon Excitation $4 \mathrm{Pi}$ Confocal Microscope - Enhanced Axial Resolution Microscope for Biological Research," Appl. Phys. Lett. 66, 1698-1700 (1995).

[23] W. Denk, J. H. Strickler, and W. W. Webb, "2-Photon Laser Scanning Fluorescence Microscopy," Science 248, 73-76 (1990).

[24] P. E. Hanninen, E. Soini, and S. W. Hell, “Continuous-wave excitation 2-photon fluorescence microscopy," J. Microsc. 176, 222-225 (1994).
[25] P. E. Hanninen, and S. W. Hell, "Luminescence-scanning microscopy process and a luminescence scanning microscope utilizing picosecond or greater pulse lasers" U.S. Patent US 5777732 (1998).

[26] P. Hänninen, A. Soini, N. Meltola, J. Soini, J. Soukka, and E. Soini, "A new microvolume technique for bioaffinity assays using twophoton excitation," Nat. Biotechnol. 18 (5), 548-550, 2000.

[27] P. E. Hänninen, and E. J. Soini, "A biospecific assay method" WIPO Patent W01996027798A1 (1996).

[28] P. E. Hänninen, and E. J. Soini, “Biospecific multiparameter assay method," U.S. Patent US5891738 (1999).

[29] S. W. Hell, "Improvement of lateral resolution in far-field fluorescence light microscopy by using two-photon excitation with offset beams," Opt. Commun. 106 (1-3), 19-24 (1994).

[30] S. W. Hell, and J. Wichmann, "Breaking the Diffraction Resolution Limity by Stimulated-Emission - Stimulated-Emission-Depletion Fluorescence Microscopy," Opt. Lett. 19, 780-782 (1994).

[31] S. W. Hell, and M. Kroug, "Ground-state-depletion fluorscence microscopy: A concept for breaking the diffraction resolution limit," Appl. Phys. B Lasers 0. 60 (5), 495-497 (1995).

[32] P. E. Hänninen, L. Lehtelä, and S. W. Hell, "Two- and multiphoton excitation of conjugate-dyes using a continuous wave laser," 0 pt. Commun. 130, 29-33 (1996).

[33] A. Schonle, P. E. Hanninen, and S. W. Hell, “Nonlinear fluorescence through intermolecular energy transfer and resolution increase in fluorescence microscopy," Ann. Phys. 8, 115-133 (1999).

[34] K. I. Willig, B. Harke, R. Medda, and S. W. Hell, "STED microscopy with continuous wave beams," Nat. Methods 4, 915-918 (2007).

[35] C. M. Christensen, The Innovator's Dilemma (Harvard Business School Press, Boston, 1997).

[36] A. Maxmen, "Taking risks to transform science," Cell 139 (1), 13-15 (2009).

[37] S. Jobs, "Text of Steve Jobs' Commencement address (2005)." http://news.stanford.edu/news/2005/june15/jobs-061505.html [Accessed: 26-Jan-2015]. 